\title{
Clonal growth and demography of a hemicryptophyte alpine plant: Leontopodium alpinum Cassini
}

\author{
Roland Keller • Pascal Vittoz
}

Received: 8 April 2014/Accepted: 31 October 2014/Published online: 2 December 2014

(c) Swiss Botanical Society 2014

\begin{abstract}
Clonally reproducing hemicryptophytic rosette plants are common in the alpine belt. However, their demography and, indirectly, their growth and reproductive strategy in these harsh conditions were rarely studied. We analysed the morphology, clonal reproduction and demography of one such species, Leontopodium alpinum, in two populations of the Swiss Alps. The species forms small colonies of 1-5 (maximum 30 ) sterile rosettes with a few flowering stalks. After flowering, the apical meristem dies and one or two new axillary buds grow below the previous rosette in the following year, developing into short rhizomes $(<2 \mathrm{~cm})$, which decay after 4 years. The new stalk produces sterile rosettes before flowering after 2-4 years, depending on climatic conditions. The apical meristem often dies during the sterile stage, and is replaced by a new axillary bud. Levkovitch matrices on two stages (sterile and flowering rosettes) showed that rosette survival and clonal reproduction maintain long-lived populations $(\lambda=0.96)$. Elasticities indicated that a change in the survival of sterile rosettes had the strongest effect on population dynamics, and this stage lasts, on average, 6.8 years at $2,480 \mathrm{~m}$. Altogether, L. alpinum is following Tomlinson's architectural model. This growth form appears perfectly adapted to harsh alpine conditions: the
\end{abstract}

Electronic supplementary material The online version of this article (doi:10.1007/s00035-014-0142-y) contains supplementary material, which is available to authorized users.

\section{R. Keller}

Ch. de Primerose 6, 1007 Lausanne, Switzerland

e-mail: rkeller_lausanne@yahoo.fr

P. Vittoz $(\bowtie)$

Departement of Ecology and Evolution, University of Lausanne,

Biophore, 1015 Lausanne, Switzerland

e-mail: pascal.vittoz@unil.ch clonal ramification ensures longevity to genets and the semelparous behaviour of the rosettes allows an efficient flowering, whatever the climatic conditions. L. alpinum appears to follow a common growth model among rosette possessing hemicryptophytes in the alpine belt.

Keywords Architecture - Growth pattern · Inflorescence development - Levkovitch matrix . Life cycle $\cdot$ Morphology $\cdot$ Switzerland

\section{Introduction}

Demography of plants is important to understand reproductive strategies, fluctuations of populations in different ecological conditions or for conservation managements. The demography of many species has been described in these last decades (see Silvertown et al. 1993; Erhlén and Lehtilä 2002; García et al. 2008; Salguero-Gómez and Casper 2010 for articles based on large data sets) and models were developed to calculate different parameters of plant demography (Caswell 2001). However, probably for reasons of accessibility and due to their slow development, the growth and demography of arctic and alpine species have been little studied. Most studies concern dominant species, such as Carex bigelowii (Callaghan 1976), C. curvula (Erschbamer and Winkler 1995) or Geum reptans (Weppler et al. 2006; de Witte et al. 2011), although subordinate species constitute the largest part of species diversity. Demographic studies have focussed on cushion plants, such as Diapensia lapponica (Molau 1997); Minuartia obtusiloba, Paronychia pulvinata and Silene acaulis (Morris and Doak 1998, 2004), because of their remarkable adaptive traits, but more rarely on hemicryptophytes (Kuss et al. 2008). Moreover, these studied species depend on sexual 
reproduction, although vegetative reproduction (Weppler et al. 2006; Pellissier et al. 2010) and hemicryptophytes are very common in the alpine belt (Bliss 1971; Aeschimann et al. 2012). Among alpine hemicryptophytes, approximately one-third of the species have mostly leaves reduced to a rosette on the ground (Matteodo et al. 2013), to take advantage of the warm soil temperatures and of the protection from snow in winter (Körner 2003) and because they are more difficult to graze for large herbivores. This leaf morphology is particularly frequent in open alpine grasslands, although rarely dominant in species cover.

Leontopodium alpinum is one of these subordinates, rosettes possessing hemicryptophytes, ranging from the Pyrenees to the Central Balkans in Bulgaria (Wagenitz 1979). It is an 8-20 cm high perennial herb, with 2-10 small yellow capitula surrounded by white and woolly bracts (Aeschimann et al. 2004). As it is rare and often grows on rocks or steep slopes (Rey et al. 2011; Ischer et al. 2014), it is valued as a symbol of the Alps and is often prized by tourists and botanists (Erhardt 1993); its common German name, edelweiss, means noble (edel) and white (weiss; Dweck 2004). Following decades of collection by tourists, the species is now considered endangered and is protected in most countries and regions where it grows (Rey et al. 2011; http://www.infoflora.ch/). A better understanding of the ecology, growth and demography is thus essential for a better conservation of the species (Arlettaz et al. 2010).

Despite the symbolic value of L. alpinum in the Alps, it has rarely been studied and only few articles are dedicated to its reproduction or ecology. Erhardt (1993) observed that bracts and flowers attract a wide range of insects, but $88 \%$ of pollination is due to flies. Recently, Ischer et al. (2014) demonstrated the importance of base-rich bedrocks (limestone or ultramafic rocks) and a low grass cover. As a shortgrowing, heliophilous species, L. alpinum has a low competitive ability and grows in conditions, where other dominant species fail.

As far as we know, the clonal growth and demography of L. alpinum have never been studied in detail. Rey et al. (2011) stated that a blackish rhizome is rapidly produced after germination, with numerous slender, adventitious roots. The rhizome produces a rosette in the first year and survives to winter. In June of the second year, a flowering stalk develops and flowers bloom in mid-July (Rey et al. 2011). Hence, an inflorescence could be expected on every second rosette. However, at natural sites, the proportion of flowering rosettes is much lower and a longer lag before rosettes are flowering is suspected.

The aims of this study were to describe the clonal growth and demography of a subordinate, rosettes possessing alpine hemicryptophyte using L. alpinum as an example. More precisely, we aimed to understand how clonal reproduction helps these species to develop and reproduce in the conditions met in alpine grasslands (short summers, temperatures close to the lower threshold for plant growth and reproduction). More specifically, we ask the following questions: (1) At what frequency do growing plants produce flowering stalks, or conversely, how long does a particular rosette grow before flowering? (2) How long can rosettes and shoots live? (3) How does L. alpinum use clonal reproduction to survive or colonise new area? (4) Is there a relationship between rosette density and flowering probability (density dependence)? These questions were addressed in the context of a broader study on L. alpinum (Keller and Vittoz 2010; Ischer et al. 2014) by monitoring three populations in the Western Swiss Alps. A few individuals were uprooted for a description of architecture and colonies were monitored by mapping individuals between 2008 and 2012. Demography was assessed using matrix modelling (Caswell 2001).

\section{Methods}

Study area

Two alpine pastures were selected in Val Ferret (Fig. 1); one at Arpalle de la Fouly (WSW aspect, 2,360 m a.s.1.) and the other at Dotse, a small mountain peak (SSE aspect, 2,480 m a.s.1.). Both sites consist of calcschistes, with a high total rainfall ( $>2,000 \mathrm{~mm} /$ year). The vegetation is dominated by dry alpine grasslands on limestone (Seslerion in Delarze and Gonseth 2008; Keller and Vittoz 2010). These grasslands are traditionally grazed by sheep from mid-July to the end of September.

At both sites, an area of approximately $550 \mathrm{~m}^{2}$ has been fenced within large populations of L. alpinum to protect the monitoring device. Nine, $1 \mathrm{~m}^{2}$ plots at Arpalle and 15 plots at Dotse were distributed among L. alpinum populations to

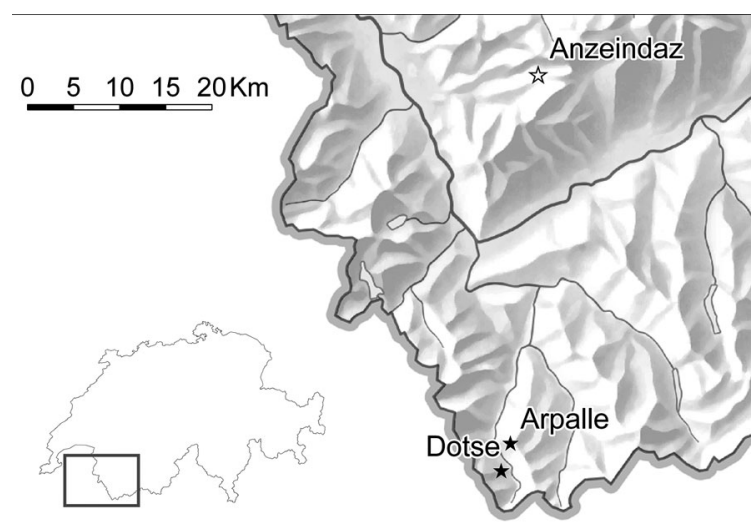

Fig. 1 Location of the studied populations of Leontopodium alpinum in Switzerland. Detailed monitoring (maps of individual plants) was realised at Arpalle and Dotse and flowering and sterile rosettes were counted in the three populations 
monitor the number of individuals and the composition of plant communities (Keller and Vittoz 2010).

An additional site was selected at Anzeindaz (Fig. 1), where a small population of $L$. alpinum is scattered throughout $400 \mathrm{~m}^{2}$ close to the mountain summit (ESE aspect, 2,160 $\mathrm{m}$ a.s.l.) on hard limestone, but with a similar vegetation and amount of rainfall as at the other sites.

\section{Morphological observations}

As L. alpinum is a protected species in Switzerland, only ten small groups of 1-3 rosettes at Arpalle and Dotse and two at Anzeindaz were uprooted for a description of the growth pattern. Uprooted shoots were cleaned and were longitudinally cut to describe ramifications and to count growth units.

\section{Population dynamics}

L. alpinum populations at Arpalle and Dotse were monitored at the level of entire populations and the level of individual colonies (group of rosettes). Monitoring at the population scale was based on all individual rosettes present in the $1 \mathrm{~m}^{2}$ plots. Rosettes were counted each year (2008-2011) and were identified as sterile or flowering.

On the basis of previous morphological observations, a colony was defined as a group of rosettes separated by $<3 \mathrm{~cm}$. Genets cannot be identified in the field, because a short longevity of rhizomes after ramification ( $\sim 4$ years $)$ induces a physiological separation between rosettes of the same colony. Monitoring of rosette position was carried out with a precision of $\pm 1 \mathrm{~cm}$ for each rosette, with the help of wooden sticks set in the plots as land marks (see example in Online Resource 1). This allowed to detecting the connections between rosettes in two successive years, from 2009 to 2012. 100 colonies (ca. 250 rosettes) distributed among nine plots at Arpalle and 80 colonies (ca. 160 rosettes) in 13 plots at Dotse were randomly selected in 2009. Very dense colonies were avoided because of difficulties in rosette mapping. As only areas occupied by monitored colonies were mapped, no seedlings in these restricted areas were recorded. Some seedlings were observed in the plots but these were rare and difficult to detect. Moreover, we considered that the recorded seedlings could not be attributed precisely to one of the colonies (seed dispersal) and thus, we preferred not to consider them in transition matrices.

Because of the impossibility of identifying rosette age (no regular increase in size, and flowering rosettes similar in size to sterile ones), stage-based Levkovitch matrices (Caswell 2001) were used to model population dynamics. Two stages were recognised (sterile rosettes irrespective of the size, and flowering rosettes), giving four possible transitions in the matrices: $p_{11}$, the probability for a sterile rosette to produce another sterile rosette; $p_{12}$, the probability for an apical meristem to develop into an inflorescence (flowering rosette); $p_{21}$, the probability of development of new sterile rosettes after blooming; $p_{22}$, the probability of development of a new inflorescence after blooming. With the morphological description of uprooted individuals, it appears that it was not possible to distinguish morphologically if the transition from sterile rosette to sterile rosette $\left(p_{11}\right)$ was due to the development of the apical meristem into a new growth unit (monopodial growth; Fig. 2a) or to sympodial ramification relying on the growth of an axillary bud (1-year-old shoot; Fig. 2b). Conversely, as the apical meristem disappears in flowering shoots, new sterile rosettes $\left(p_{21}\right)$ are always due to sympodial ramification (clonal reproduction), and because of the impossibility for 1-year-old shoot to bloom (at least at high elevations), $p_{22}$ equals always 0 . Three periods of transitions (2009-2010, 2010-2011, 2011-2012) were considered and mean matrices were used to calculate deterministic growth rates. The "age or residence" in sterile rosette stage was calculated according to the formula of Barot et al. (2002): age of residence $=1 /\left(1-p_{11}\right)$. The deterministic growth rate $\left(\lambda_{\mathrm{D}}\right)$ and the elasticity (relative contribution of the $\mathrm{p}_{\mathrm{ij}}$ demographic parameter to the annual population growth rate; de Kroon et al. 1986) were calculated according to Caswell (2001). According to Morris and Doak (2002), we calculated the stochastic growth rate $\left(\lambda_{\mathrm{s}}\right)$, based on Tuljapurkar's approximation, and the probability of extinction, with the 2009 inventories as initial populations and a threshold of quasiextinction of 10 individuals. Growth rates, elasticity and quasi-extinction probability were calculated using the library popbio in R (Stubben and Milligan 2007).

At Anzeindaz, L. alpinum was only monitored at the population level, with annual (2008-2011) counting of all sterile and flowering rosettes in the entire population $\left(\sim 400 \mathrm{~m}^{2}\right)$.

Flowering rate in relation to colony size

The influence of colony size on flowering rate was tested by pooling results for each site for the 3 years (2010-2012) of monitoring. The number of flowering rosettes (FR) was related to the total number of rosettes (TR) in the colony according to different analyses: (a) each colony was considered separately and (b) colonies were pooled by rosette number (mean proportion of FR for a given TR). Then, two different kinds of linear regressions at each site were calculated: $\mathrm{FR} \sim \mathrm{TR}$ and $\mathrm{FR} \sim \log (\mathrm{TR})$. 


\section{Results}

Morphology and development

Longitudinally cut shoots from Val Ferret show a rhythmic variation in internode length, which allows the numbering of the sequential growth units. The simplest life cycle of a L. alpinum shoots in Val Ferret starts with the development of a sterile rosette from a below-ground axillary bud (Fig. 2a). Leaves persist during only one season and are observed the next spring as decaying leaves on previous shoots. In the second year, monopodial growth leads to a new sterile rosette, with new leaves, and in the third year, the shoot has the ability to bloom. Adventitious, thin roots usually develop from the growth units of the antepenultimate year.

Development is, however, rarely straightforward and the apical meristem often dies, with successive growth occurring by sympodial ramification (Fig. 2b). The new rosette grows very close to the location of the dead 'mother' rosette, rarely further than $2 \mathrm{~cm}$. However, two simultaneous ramifications, or ramification from an older growth unit may occur. Growth units older than 2 years appear to lose the ability to produce new lateral shoots. Hence, different development patterns can be observed, such as flowering in the second year, as observed in
Anzeindaz (Fig. 3a), or in the third year (Fig. 3b), or 3-year-old sterile rosettes (Fig. 3c).

It was not possible to deduce shoot age from rosette size, and small rosettes can be formed on old shoots. Presumably, 4-year-old shoots begin to decay at the base, which leads to the disruption of physiological connections. Hence, L. alpinum, with its slender rhizomes and thin roots is easily uprooted.

\section{Dynamics of populations}

The proportion of flowering shoots varied with time and location, but is globally low. Inventories at the population scale showed that $8.4-24.3 \%$ of the rosettes flowered (mean $\pm \mathrm{SD}=17.1 \pm 6.9 \%$ ) at Arpalle, from a relatively constant total of rosettes (375-411; Fig. 4a). This proportion is close to that at Dotse, where 8.1-18.3\% of rosettes flowered $(13.3 \pm 4.2 \%)$, from a lower and slightly increasing total number (246-289). In both populations, the proportion of flowering shoots was highest in 2008 and lowest in 2010. The population of Anzeindaz showed a contrasting pattern, with a higher proportion of flowering shoots (18.9-40.2, $28.6 \pm$ $9.5 \%)$ and a strongly fluctuating population size, however, with a trend towards a decreasing proportion of flowering rosettes.
Fig. 2 Possible annual development of Leontopodium alpinum. a The year after flowering, an axillary bud develops a new sterile rosette; in the second year, monopodial growth maintains the sterile rosette and in the third year the plant develops a new flowering shoot. b The sterile rosette dies $(+)$, and a new sterile rosette grows from the sympodial development of an axillary bud; the third year, new death of the terminal bud and new sympodial development of two sterile rosettes. GU1, GU2, GU3 first, second and third annual growth units, $b$ axillary bud, $r$. $a d v$. adventitious roots a

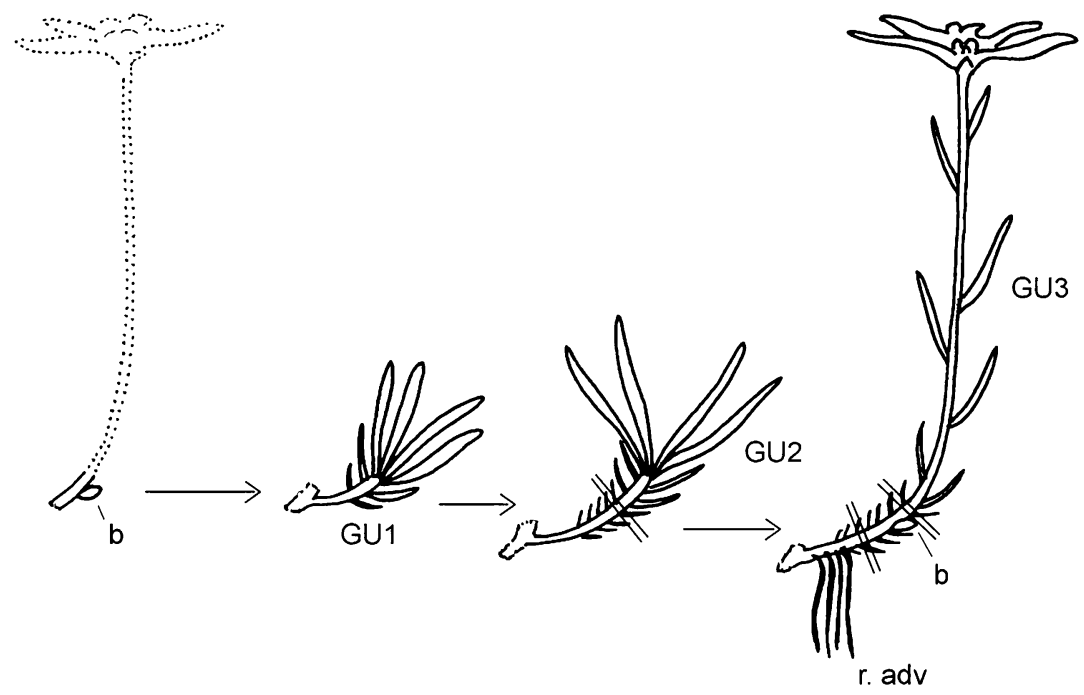

b
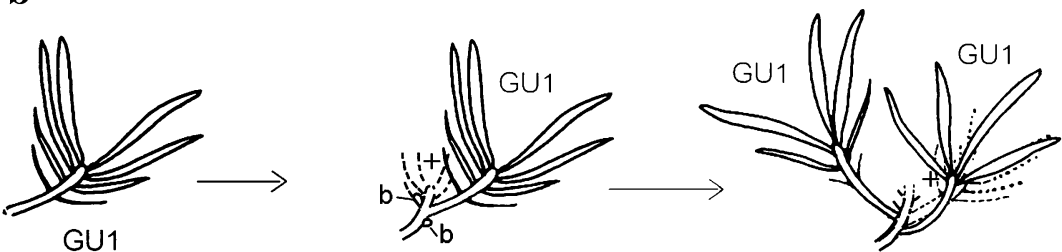
Fig. 3 Closer view of different shoot stages of Leontopodium alpinum. a Flowering the second year; $\mathbf{b}$ flowering the third year; c 3-year-old vegetative shoot. $A 1$ : axis (rhizome); $A 2$ (A3): axes developed from an axillary bud of $A 1$ (A2); GU1, GU2, GU3 first, second and third annual growth units; $L$ living leaves, $d l$ decaying leaves of previous years; $b$ axillary bud, $r$. $a d v$. adventitious roots
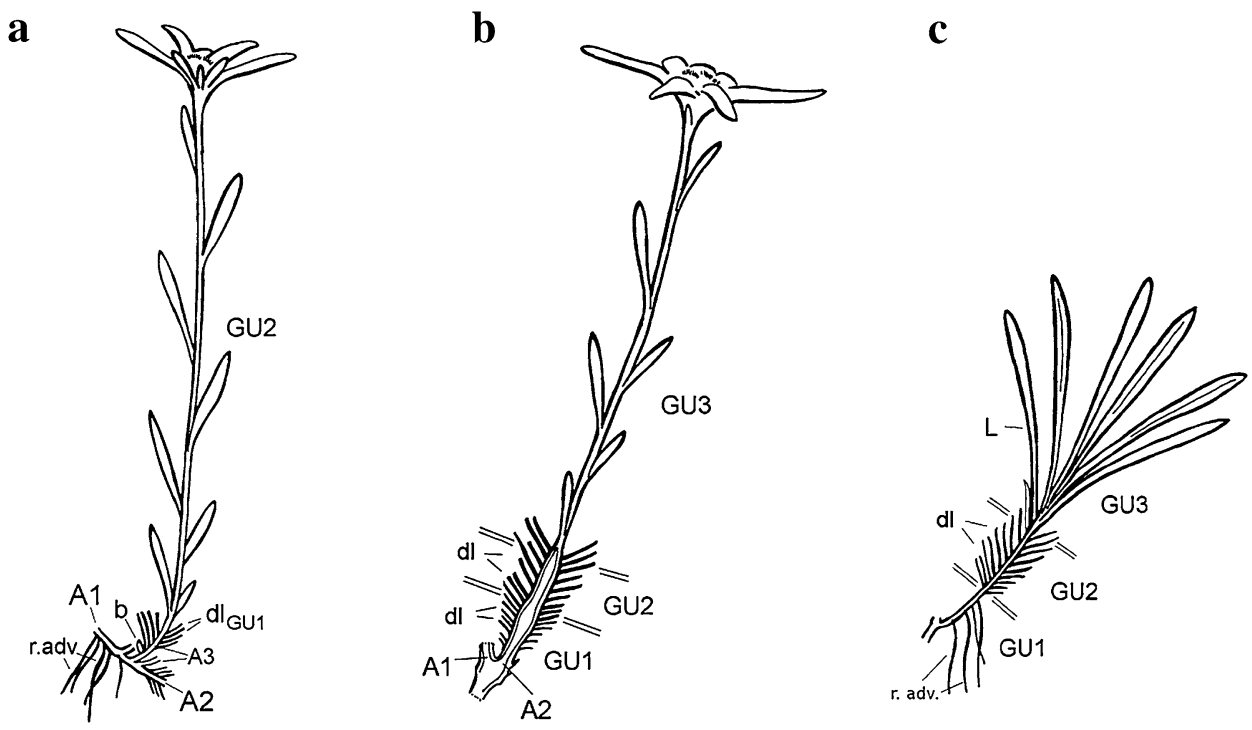

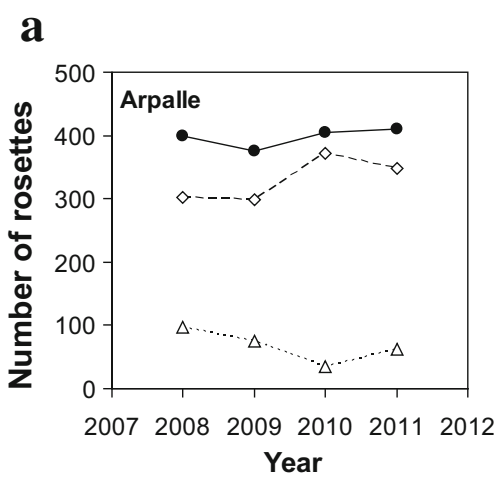

Fig. 4 Fluctuations, from 2008 to 2011, in rosette numbers (sterile, flowering, total) of L. alpinum in $1 \mathrm{~m}^{2}$ plots at a Arpalle $(2,365 \mathrm{~m}$ a.s.l., $n=10)$ and b Dotse $(2,480 \mathrm{~m}, n=13)$, and for the whole

\section{Dynamics of colonies}

Colonies consisted of 1-30 rosettes, with a mean size of $4.4 \pm 3.7$ rosettes at Arpalle and $3.3 \pm 3.1$ at Dotse. Demography of colonies from 2009 to 2012 is summarised in Table 1. At each site, the demography of colonies appears to depend mainly on the growth of new sterile rosettes after flowering. Indeed, sterile rosettes showed a relatively low proportion of winter survival (either by growth at the apical meristem or by ramification after death of the meristem) of 0.766 at Arpalle and 0.853 at Dotse ( $p_{11}$ in Table 1$)$. Some of the surviving rosettes flowered $\left(p_{12}, 0.150\right.$ at Arpalle, 0.097 at Dotse), but the death rate at the stage of sterile rosette (0.225 at Arpalle, 0.140 at Dotse) exceeded the flowering rate. These values fluctuated between years, but the differences between populations were quite stable. Conversely, the mean number of new sterile rosettes formed after flowering always exceeded $1\left(p_{21}, 1.182\right.$ at Arpalle, 1.093 at population c at Anzeindaz $(2,160 \mathrm{~m})$. Corresponding values of population growth rates are given in Online Resource 2

Dotse). The death rate after flowering (i.e. death of the rosette without development of new axillary buds) was lower (0.113 at Arpalle, 0.107 at Dotse; Table 1) than that for sterile rosettes.

A small number of rosettes from uncertain origin ( $\mathrm{X}$ in Table 1) were observed. These were found in monitored colonies, but were too far away from previous rosettes to consider that they originated from them. A new establishment from seeds is unlikely, as no seedlings were observed.

Monitoring new sterile rosettes produced after flowering showed that they will never bloom the following year and rarely 2 years later. In other words, a flowering shoot is usually at least 3 years old.

In summary, the population at Arpalle, compared with that at the Dotse, produced fewer new rosettes from sterile shoots $\left(p_{11}\right.$ in Table 1$)$ and lost more rosettes (death rate sterile rosettes in Table 1). This trend was counterbalanced by a higher production of lateral shoots after flowering $\left(p_{21}\right)$. 
Table 1 Demography at the colony scale of Leontopodium alpinum ( $n=100$ at Arpalle, $n=80$ at Dotse) between 2009 and 2012

\begin{tabular}{|c|c|c|c|c|c|c|c|c|}
\hline & \multicolumn{4}{|l|}{ Arpalle } & \multicolumn{4}{|l|}{ Dotse } \\
\hline & 2009-2010 & 2010-2011 & $2011-2012$ & $\begin{array}{l}\text { Mean } \\
\text { 2009-2012 }\end{array}$ & 2009-2010 & 2010-2011 & 2011-2012 & $\begin{array}{l}\text { Mean } \\
\text { 2009-2012 }\end{array}$ \\
\hline Pool-st & 173 & 185 & 167 & & 128 & 145 & 130 & \\
\hline S1 & 99 & 101 & 91 & & 90 & 106 & 85 & \\
\hline S2 & 15 & 11 & 10 & & 12 & 3 & 11 & \\
\hline $\mathrm{X}$ & 13 & 14 & 12 & & 3 & 5 & 2 & \\
\hline $\mathrm{F}$ & 25 & 33 & 21 & & 12 & 13 & 14 & \\
\hline Ds & 34 & 41 & 43 & & 14 & 24 & 19 & \\
\hline $\mathrm{V}=\mathrm{S} 1+2 \cdot \mathrm{S} 2+\mathrm{X}$ & 142 & 137 & 123 & & 117 & 117 & 109 & \\
\hline$p_{11}=\mathrm{V} /$ Pool-st & 0.821 & 0.741 & 0.737 & 0.766 & 0.914 & 0.807 & 0.838 & 0.853 \\
\hline$p_{12}=\mathrm{F} /$ Pool-st & 0.145 & 0.178 & 0.126 & 0.150 & 0.094 & 0.090 & 0.108 & 0.097 \\
\hline Death rate sterile rosettes $=$ Ds $/$ Pool-st & 0.197 & 0.222 & 0.257 & 0.225 & 0.109 & 0.166 & 0.146 & 0.140 \\
\hline Pool-fl & 36 & 25 & 33 & & 25 & 12 & 13 & \\
\hline $\mathrm{R} 1$ & 19 & 18 & 22 & & 12 & 9 & 10 & \\
\hline $\mathrm{R} 2$ & 12 & 6 & 8 & & 8 & 2 & 2 & \\
\hline $\mathrm{Df}$ & 6 & 2 & 3 & & 4 & 1 & 1 & \\
\hline$p_{21}=(\mathrm{R} 1+2 \cdot \mathrm{R} 2) /$ Pool-fl & 1.194 & 1.200 & 1.152 & 1.182 & 1.120 & 1.083 & 1.077 & 1.093 \\
\hline $\begin{array}{l}\text { Death rate flowered rosettes = Df/ } \\
\text { Pool_fl }\end{array}$ & 0.167 & 0.080 & 0.091 & 0.113 & 0.160 & 0.083 & 0.077 & 0.107 \\
\hline Pool-tot & 209 & 210 & 200 & & 153 & 157 & 143 & \\
\hline Veget. reproduction rate & 1.005 & 0.952 & 0.910 & 0.956 & 1.026 & 0.911 & 0.958 & 0.965 \\
\hline $\begin{array}{l}\text { Death rate all rosettes }=(\mathrm{Ds}+\mathrm{Df}) / \\
\text { Pool-tot }\end{array}$ & 0.191 & 0.205 & 0.230 & 0.209 & 0.118 & 0.159 & 0.140 & 0.139 \\
\hline
\end{tabular}

Each column gives the number of rosettes in the previous year (e.g. 2009 in the first column, shifted to the left) and the destiny of these rosettes in the current year (e.g. 2010 in the first column). The monitoring of two colonies is illustrated in Online Resource 1

Pool-st, number of sterile rosettes in the previous year. In the current year, these sterile rosettes have the following possible destiny: S1 new single sterile rosettes growing after a rosette, $S 2$ pairs of sterile rosettes growing after a single rosette, $X$ new rosettes, not clearly related to previous rosettes, $F$ flowering rosettes, $D s$ dead rosettes (nothing found at the previously occupied position), $V$ total number of new sterile rosettes; $p_{11}$ and $p_{12}$ : values for the transition matrices (see Table 2)

Pool-fl, number of flowering rosettes in the previous year. In the current year, these flowering rosettes have the following possible destiny: $R 1$ new single sterile rosettes growing after a flowering rosette, $R 2$ pairs of sterile rosettes growing after a flowering rosette, $D f$ dead rosettes (nothing found at the previously occupied position by a flower), $p_{21}$ value for the transition matrices (see Table 2)

Pool-tot, total number of rosettes in the previous year (Pool-st + Pool-fl); Veget. reproduction rate, vegetative reproduction rate calculated as the total number of new rosettes by Pool-tot

On average, the residence time for the sterile rosette stage was 4.3 years at Arpalle and 6.8 years at Dotse.

\section{Growth rate and elasticity}

The deterministic growth rate $\lambda_{\mathrm{D}}$ from the mean Levkovitch transition matrix (Table 2) was 0.952 at Arpalle and 0.963 at Dotse. The stochastic growth rate $\lambda_{\mathrm{S}}$ was 0.891 (confidence interval 0.8906-0.8921) at Arpalle and 0.915 (CI $0.9146-0.9162$ ) at Dotse. These values correspond to a $50 \%$ risk of quasi-extinction ( $<10$ rosettes) in 74 years at Arpalle and 87 years at Dotse, without including sexual reproduction (see details in Online Resource 3).
Elasticities were similar in both stands (Table 2), with the highest value for $p_{11}$ (development of a new sterile rosette from a sterile rosette by monopodial growth or sympodial ramification) and the lowest for $p_{12}$ (development of a flowering shoot). Hence, $\mathrm{p}_{11}$ was the parameter with the strongest effect on $\lambda$.

Flowering rate and colony size

In linear regressions, the number of flowering rosettes showed the best relation with the logarithm of colony size. The proportion of flowering rosettes decreased exponentially with increasing colony size. This was observed when 
Table 2 Transition matrices and elasticities for two populations of L. alpinum between 2009 and 2012

\begin{tabular}{|c|c|c|c|c|c|c|c|c|c|c|}
\hline \multicolumn{11}{|c|}{$\begin{array}{lll}\text { General structure } & p_{11} & p_{21} \\
p_{12} & p_{22}\end{array}$} \\
\hline & \multicolumn{8}{|c|}{ Transition matrices } & \multicolumn{2}{|c|}{ Elasticities } \\
\hline & \multicolumn{2}{|c|}{ 2009-2010 } & \multicolumn{2}{|c|}{ 2010-2011 } & \multicolumn{2}{|c|}{ 2011-2012 } & \multicolumn{2}{|l|}{ Mean } & & \\
\hline \multirow[t]{2}{*}{ Arpalle } & 0.821 & 1.194 & 0.741 & 1.200 & 0.737 & 1.152 & 0.766 & 1.182 & 0.673 & 0.163 \\
\hline & 0.145 & 0 & 0.178 & 0 & 0.126 & 0 & 0.150 & 0 & 0.163 & 0 \\
\hline \multirow[t]{2}{*}{ Dotse } & 0.914 & 1.120 & 0.807 & 1.083 & 0.838 & 1.077 & 0.853 & 1.093 & 0.794 & 0.103 \\
\hline & 0.094 & 0 & 0.090 & 0 & 0.108 & 0 & 0.097 & 0 & 0.103 & 0 \\
\hline
\end{tabular}

Matrices follow the general structure, where $p_{11}$ is the probability for a sterile rosette to produce a sterile rosette (by monopodial growth of the rhizome or sympodial ramification after death of the apical meristem), $p_{12}$ is the probability for an apical meristem to develop into a flowering shoot and $p_{21}$ is the probability of development of new sterile rosettes from a flowering shoot; $p_{22}$ is 0 because of the death of the apical meristem after flowering. Elasticities are calculated from the mean transition matrices

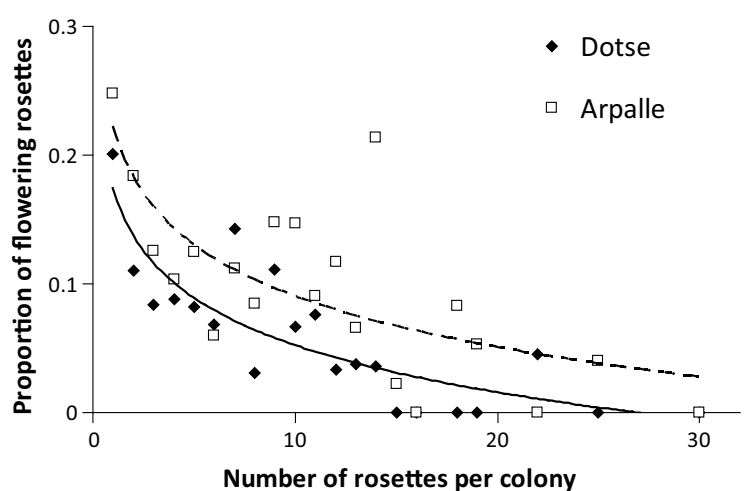

Fig. 5 Proportion of flowering rosettes (Prop FR) in relation to colony size (TR total number of rosettes in the colony) at Arpalle and Dotse. Data are pooled by colony size for 3 years of observations (2010-2012). The interrupted line is the linear regression on the logarithm of colony size at Arpalle (Prop FR $=-0.050 \cdot \log (\mathrm{TR})+$ 0.212 ) and the continuous line is the same regression at Dotse (Prop $\mathrm{FR}=-0.053 \cdot \log (\mathrm{TR})+0.174)$

colonies were considered individually (Arpalle: $R^{2}=0.036, p<0.001$; Dotse: $\left.R^{2}=0.029, p<0.001\right)$ as well as when colonies where pooled by rosette number for the 3 years of observations (Arpalle: $R^{2}=0.437$, $p=0.002$; Dotse: $R^{2}=0.695, p<0.001$; Fig. 5). Regressions with colonies considered individually had a lower $R^{2}$ because of the high proportion of colonies without any flowering rosette (66.9\% at Arpalle and $77.4 \%$ at Dotse).

\section{Discussion}

L. alpinum reproduces mainly clonally, either by ramification of shoots after death of the apical meristem, or from the development of axillary buds at the base of a flowering shoot. This growth pattern is similar to Tomlinson's architectural model (Tomlinson 1983) and the short, hypogeotropic rhizomes correspond to type nine according to the typology of Klimeš et al. (1997). The decay of the underground rhizome connections after approximately 4 years separates the genets into two or more genetically similar but not connected parts. This clonal reproduction, with frequent double ramifications ( $\mathrm{R} 2$ and $\mathrm{S} 2$ in Table 1), compensates for the high mortality of the apical meristems and the semelparous behaviour of the rosettes. This high mortality rate confers a short longevity to the ramets, not exceeding 5-7 years in the observed populations. In accordance, Erhlén and Lehtilä (2002) showed that the ramets of arctic and alpine species live no longer than those of lowlands species. However, when considering genets, edelweiss is probably very long lived, as are many other alpine herbs (Morris and Doak 1998; de Witte et al. 2011).

Clonal reproduction by rhizomes is very common in alpine plant species (Bliss 1971; Klimeš et al. 1997), although rarely documented. The combination of clonal reproduction with short-lived ramets, or other parts of genets, is probably a frequent strategy in alpine ecosystems for hemicryptophytes with rosettes. As far as we know, the advantages of such a growth pattern have never been discussed for development in stressful conditions, as they occur in the alpine belt. Kim and Donohue (2011) observed it for Erysimum capitatum in USA, whereas the species was completely semelparous at lower elevations. Personal observations by isolating some individuals from the same plant communities as L. alpinum in Val Ferret showed that Aster alpinus L., Campanula barbata L, Campanula scheuchzeri Vill., Erigeron uniflorus L., Hieracium angustifolium Hoppe, Leontodon helveticus Mérat, Phyteuma orbiculare L., Senecio incanus L., and Scabiosa lucida Vill., all hemicryptophytes with rosettes, appear to share the same strategy of development. Indeed, this strategy allows the use of the long longevity of clonal reproduction and the advantages of a hapaxanthic flowering, where seed production is maximised by a possibly long sterile stage of the rosette to accumulate carbohydrate stores for sexual reproduction (Kuss et al. 2008; Young and Augspurger 1991). This might be particularly important for alpine species that 
have often relatively large inflorescences compared to the vegetative part (Körner 2003).

Without any possibility to visually assess the age of rosettes, it is not possible to record their age at flowering without destructive sampling. Uprooted plants in Val Ferret showed the development of a flowering shoot after 3 or 4 years, whereas the calculated age of residence in sterile rosette stage was 4.3-6.8 years. These last values are more in accordance with the records of $13-17 \%$ of flowering rosettes than a theoretical 25-33\% based on observed ages. The difference is due to the high mortality rate of apical meristems and to a possibly longer sterile development for some rosettes. Colonies in Anzeindaz were not precisely monitored, but we can expect them to bloom earlier because of the higher proportion of flowering rosettes (26.2\%). Indeed, the two uprooted plants were 2 years old. The lower elevation (2160 $\mathrm{m}$ instead of 2,365-2,480 $\mathrm{m}$ in Arpalle and Dotse) implies warmer conditions and a longer growing season. Similarly, some of the cultivated plants at about 1,300 $\mathrm{m}$ are able to bloom in the first year (Rey et al. 2011). This demonstrates the ability of plants to delay flowering as long as the necessary threshold of size or storage is not reached, and probably to ensure a sufficient number and fitness of flowers, irrespective of the climatic conditions. The fluctuations in the proportion of flowering plants probably correspond to yearly climatic conditions. A longer duration of monitoring would be necessary to correlate these fluctuations with temperature and rainfall.

Clonal reproduction plays an essential role to maintain $L$. alpinum populations. Indeed, without including sexual reproduction, the population growth rates at the colony scale $\left(\lambda_{\mathrm{S}}=0.89-0.92\right)$ correspond to a potential survival of the populations of 70-90 years. Clonal reproduction is particularly important by the development of new rosettes from axillary ramification after flowering, with high values in transition matrices from flowering to sterile rosettes $\left(p_{21}=1.093-1.182\right)$. This provides the species with a potentially long life span at the genet level, and potential immortality (Hamilton et al. 1987), which was correlated many times with growth in harsh or extreme conditions, such as in the alpine belt, or with the stable conditions met in the climax (Forbis and Doak 2004; García et al. 2008; Marcante et al. 2009). The importance of survival in these conditions was also apparent from the highest elasticity value attributed to $p_{11}$, transition from sterile rosette to sterile rosette (Marcante et al. 2009). The typical plant communities where L. alpinum grows (Seslerion, Caricion firmae or Elynion; Ischer et al. 2014), are all characterised by difficult conditions for plant growth. Winters are long and plants are not always protected from frost by snow, due to the steep, southerly exposed slopes or the windy ridge situations.

Although sexual reproduction was not considered in our monitoring, it can be estimated with $3 \times 3$ transition matrices where missing parameters are simulated (proportion of seedlings) or deduced from literature (survival of seedlings; see method in Online Resource 4). To maintain stable populations $(\lambda=1)$, a sexual reproduction corresponding to approximately 0.5 seedling by flowering rosettes is necessary in both sites, and to reach the recorded mean growth rate at the population level in the same plots (1.01 at Arpalle and 1.06 at Dotse; Online Resource 2), 0.6 and 1.5 seedlings are necessary at Arpalle and Dotse, respectively. This difference between both populations reflects the limited impact of a change in the rate of sexual reproduction on population growth (elasticity $0.05-0.08$; Online Resource 4), as observed for many alpine and arctic species (Forbis and Doak 2004). Indeed, the inclusion of sexual reproduction in the transition matrix modifies only slightly elasticity values and the survival of sterile rosettes is still largely the parameter with the strongest effect on population dynamics, a characteristic shared with other alpine species (Weppler et al. 2006; Marcante et al. 2009). Hence, an important change of sexual reproduction is necessary to modify weakly $\lambda$, when all other parameters are maintained constant. Between-year fluctuations are probably due mainly to the survival of sterile rosettes and incidentally to particularly good years for seed germination and/or seedling establishment. However, more precise inventories would be necessary to determine precisely these processes and understand the necessary ecological conditions.

Intraspecific competition appears to also influence reproduction. Indeed, the proportion of flowering rosettes decreased with an increase in colony size. The high density of some colonies suggests that local resources might be overexploited, conversely to some species, such as Carex bigelowii, which can grow clonally without creating intraspecific competition (Callaghan 1976). Local overexploitation would slow the development of rosettes and in consequence, lengthen the necessary time to flowering and decrease the flowering rate. However, other explanations are possible, including genetic differences in allocation of resources. Indeed, a trade-off between the respective importance of sexual and clonal reproduction has often been observed for alpine plants (Worley and Harder 1996; Silvertown et al. 1993).

\section{Conclusions}

Leontopodium alpinum, and probably other rosettes possessing hemicryptophytes with clonal reproduction, developed an efficient strategy to cope with harsh and irregular conditions in the alpine belt. Clonal reproduction can maintain population for decades, even when conditions are not favourable for seed germination and seedling establishment. Rosettes accumulate the necessary resources 
over several years, before flowering once, with a flexibility to adapt to local and interannual variability: 1 year of growth is sometimes sufficient in favourable conditions (cultivation at low elevations, Rey et al. 2011), 2 years correspond to natural, good conditions, but at least 3-4 years are necessary at exposed sites in the alpine belt. The high variability in development causes large differences in flowering rate between populations, with a decreasing trend with increasing elevation. Changes in the survival of sterile rosettes have the strongest effect on growth rate. Although seedlings were not incorporated into models, sexual reproduction was present and is necessary for long-time survival of the populations. But, as previously observed for other alpine species, it has only minor effects on population growth rate.

This study was limited to one alpine, subordinate species. Observations of development pattern of other hemicryptophytes with rosettes in the same plant communities showed high similarities with L. alpinum, indicating probably similar growth, survival and reproduction strategies. Supplementary studies would be necessary to understand the strategy of these species, as of other important groups of subordinate species in the alpine belt such as stalked hemicryptophytes or suffruticose chamaephytes.

Acknowledgments The authors thank the Fondation Ignace Mariétan, the municipality of Orsières and the Service des Forêts et du Paysage (Valais) who helped with financial support. We are grateful to J. Stöcklin and two anonymous reviewers for their useful comments on a first draft of this manuscript.

\section{References}

Aeschimann D, Lauber K, Moser DM, Theurillat J-P (2004) Flora alpina. Belin, Paris

Aeschimann D, Rasolofo N, Theurillat J-P (2012) Analyse de la flore des Alpes. 3: biologie et phénologie. Candollea 67:5-21

Arlettaz R, Schaub M, Fournier J, Reichlin TS, Sierro A, Watson JEM, Braunisch V (2010) From publications to public action: when conservation biologists bridge the gap between research and implementation. Bioscience 60:835-842

Barot S, Gignoux J, Legendre S (2002) Stage-classified matrix models and age estimates. Oikos 96:56-61

Bliss LC (1971) Arctic and alpine plant life cycles. Annu Rev Ecol Evol S 2:405-438

Callaghan TV (1976) Growth and population dynamics of Carex bigelowii in an alpine environment. Oikos 27:402-413

Caswell H (2001) Matrix population models. Sinauer Associates Inc., Sunderland

de Kroon H, Plaisier A, van Groenendael J, Caswell H (1986) Elasticity: the relative contribution of demographic parameters to population growth rate. Ecology 67:1427-1431

de Witte LC, Scherrer D, Stöcklin J (2011) Genet longevity and population age structure of the clonal pioneer species Geum reptans based on demographic field data and projection matrix modelling. Preslia 83:371-386

Delarze R, Gonseth Y (2008) Guide des milieux naturels de la Suisse. Rossolis, Bussigny

Dweck AC (2004) A review of Edelweiss. SÖFW J 130:65-68
Erhardt A (1993) Pollination of edelweiss, Leontopodium alpinum. Bot J Linn Soc 111:229-240

Erhlén J, Lehtilä K (2002) How perennial are perennial plants? Oikos 98:308-322

Erschbamer B, Winkler J (1995) Shoot and leaf demography of Carex curvula ssp. curvula and Carex curvula ssp. rosae in the Central Alps. J Veg Sci 6:593-598

Forbis TA, Doak DF (2004) Seedling establishment and life history trade-offs in alpine plants. Am J Bot 91:1147-1153

García MB, Picó FX, Ehrlén J (2008) Life span correlates with population dynamics in perennial herbaceous plants. Am J Bot 95:258-262

Hamilton NRS, Schmid B, Harper JL (1987) Life-history concepts and the population biology of clonal organisms. Proc R Soc London 232:35-57

Ischer M, Dubuis A, Keller R, Vittoz P (2014) A better understanding of the ecological conditions for Leontopodium alpinum Cassini in the Swiss Alps. Folia Geobot. doi:10.1007/s12224-014-91908

Keller R, Vittoz P (2010) Premiers résultats d'un suivi de l'Edelweiss (Leontopodium alpinum Cass.) dans le val Ferret (Valais). Bull Murithienne 127:29-44

Kim E, Donohue K (2011) Demographic, developmental and lifehistory variation across altitude in Erysimum capitatum. J Ecol 99:1237-1249

Klimeš L, Klimešová J, Hendriks R, van Groenendael J (1997) Clonal plant architecture: a comparative analysis of form and function. In: de Kroon $\mathrm{H}$, van Groenendael J (eds) The ecology and evolution of clonal plants. Backhyus Publ, Leiden, pp 1-29

Körner C (2003) Alpine plant life. Springer, Berlin

Kuss P, Rees M, Aegisdóttir HH, Ellner SP, Stöcklin J (2008) Evolutionary demography of long-lived monocarpic perennials: a time-lagged integral projection model. J Ecol 96:821-832

Marcante S, Winkler E, Erschbamer B (2009) Population dynamics along a primary succession gradient: do alpine species fit into demographic succession theory? Ann Bot 103:1129-1143

Matteodo M, Wipf S, Stöckli V, Rixen C, Vittoz P (2013) Elevation gradient of successful plant traits for colonizing alpine summits under climate change. Environ Res Lett 8:024043

Molau U (1997) Age-related growth and reproduction in Diapensia lapponica, an arctic-alpine cushion plant. Nord J Bot 17:225-234

Morris WF, Doak DF (1998) Life history of the long-lived gynodioecious cushion plant Silene acaulis (Caryophyllaceae), inferred from size-based population projection matrices. Am J Bot 85:784-793

Morris WF, Doak DF (2002) Quantitative conservation biology: theory and practice of population viability analysis. Sinauer, Sunderland

Morris WF, Doak DF (2004) Seedling establishment and life history trade-offs in alpine plants. Am J Bot 91:1147-1153

Pellissier L, Fournier B, Guisan A, Vittoz P (2010) Plant traits covary with altitude in grasslands and forests in the European Alps. Plant Ecol 211:351-365

Rey C, Rey S, Vouillamoz J, Baroffio C, Roguet D (2011) L'Edelweiss-Reine des, fleurs edn. du Belvédère, Fleurier

Salguero-Gómez R, Casper BB (2010) Keeping plant shrinkage in the demographic loop. J Ecol 98:312-323

Silvertown J, Franco M, Pisanty I, Mendoza A (1993) Comparative plant demography-relative importance of life-cycle components to the finite rate of increase in woody and herbaceous perennials. J Ecol 81:465-476

Stubben CJ, Milligan BG (2007) Estimating and analyzing demographic models using popbio package in R. J Stat Softw 22:11

Tomlinson PB (1983) Tree architecture: new approaches help to define the elusive biological property of tree form. Am Sci 71:141-149 
Wagenitz G (1979) Compositae I: Allgemeiner Teil, EupatoriumAchillea. In: Hegi G, Conert HJ, Hamann U, Schultze-Motel W, Wagenitz G (eds) Illustrierte Flora von Mitteleuropa. Band VI, Angiospermae Dicotyledones 4, Teil 3, vol 2. Paul Parey, Berlin, pp 133-136

Weppler T, Stoll P, Stöcklin J (2006) The relative importance of sexual and clonal reproduction for population growth in the long-lived alpine plant Geum reptans. J Ecol 94:869-879
Worley AC, Harder LD (1996) Size-dependent resource allocation and costs of reproduction in Pinguicula vulgaris (Lentibulariaceae). J Ecol 84:195-206

Young TP, Augspurger CK (1991) Ecology and evolution of longlived semelparous plants. Trends Ecol Evol 6:285-289 